\title{
Research on the Optimization and Upgrading of Rural Tourism Economy Industry
}

\author{
Hao Dong ${ }^{1}$ \\ ${ }^{1}$ Shandong Vocational College of Science and Technology, Weifang, China
}

\begin{abstract}
With the rapid development of China's economy and the increase of people's material and cultural needs, the current tourism industry has received people's love. The tourism industry has become an essential way for many people to enjoy leisure and entertainment. The traditional tourism model can no longer meet the current needs of different consumer groups. Rural tourism is more and more admired by people. The rural tourism economy has become an important industry driving local economic growth. This article analyzes the rural tourism market and finds out the problems in the rural tourism industry. This article analysis the problems existing in the rural tourism industry, and provide more paths for optimizing the rural tourism economic industry under the background of China's rural revitalization.
\end{abstract}

\section{Introduction}

Rural tourism is an essential part of the rural revitalization strategy. Rural tourism needs to make indepth adjustments in terms of industry, space, operation, and economic benefits in accordance with the overall requirements of the rural revitalization strategy. It is necessary to promote the in-depth implementation of the rural revitalization strategy through the promotion and development of the rural tourism industry. In choosing the development path of rural revitalization, the key is to organically integrate the strategic intent of rural revitalization with the development direction of the rural tourism industry. Therefore, it is necessary to solve the problems that restrict the development of rural tourism, including the industrial integration system, the service system under policy innovation, and the governance system that optimizes the sharing mechanism.

\section{Development status of the rural tourism industry}

Since the 19th National Congress of the Communist Party of China proposed the strategy of rural revitalization, the issue of "agriculture, rural areas, and farmers" has attracted much attention from the state and the people. In the No. 1 Central Document in 2018, the rural revitalization strategy proposed a solution to the current contradictions in the society. General Secretary $\mathrm{Xi}$ Jinping has also delivered essential speeches, expounding the theoretical basis for implementing the rural revitalization strategy. It shows the importance of rural strategy. The implementation of the rural revitalization strategy is an important and arduous task. Among them, the focus of industrial development is restricted mainly by ecology and people's livelihood. In the new era, the development of rural tourism is to respond to the specific requirements of the country's rural revitalization strategy, and it is also an important way for China's rural areas to upgrade and develop industries.

In the current environment, China is in a transitional period of economic development. To enhance the country's rural economy's development and innovation capabilities, the Party Central Committee has proposed a series of policies on rural revitalization [1]. It provides more directions for the solution to the "three rural" issues. In recent years, the lives of farmers have improved significantly. The development of the rural tourism industry has become more rapid, and it has promoted the economic development of other industries in rural areas. However, the development of rural tourism is also facing certain problems. Among them, the homogeneity of rural tourism products is currently the most significant problem [2]. Therefore, the industrial optimization and upgrading of rural tourism is a problem that needs to be solved urgently.

\subsection{Number and proportion of rural tourism}

In recent years, China has actively promoted the development of rural tourism. In July 2019, the Ministry of Culture and Tourism and the National Development and Reform Commission jointly built some rural areas in China [3]. At present, some villages have become key villages for rural tourism in the country.

*Corresponding author: 475536334@qq.com 
Table 1. Number and Proportion of Rural Tourism in China from 2012 to 2019.

\begin{tabular}{|l|c|c|c|c|c|c|c|c|}
\hline & 2012 & 2013 & 2014 & 2015 & 2016 & 2017 & 2018 & 2019 \\
\hline $\begin{array}{l}\text { Number of Rural Tourism /100 } \\
\text { Million People }\end{array}$ & 7.3 & 10.1 & 12.5 & 22.3 & 24.5 & 29 & 31 & 39 \\
$\begin{array}{l}\text { Percentage of Total Domestic } \\
\text { Tourists /\% }\end{array}$ & 14.5 & 17.62 & 19.41 & 32.65 & 35.61 & 46.51 & 48.39 & 52.1 \\
\hline
\end{tabular}

It can be seen from Table 1 that in 2012-2018, the number of rural tourists in China has been increasing. At the end of 2018, the number of rural tourists has exceeded 3 billion, accounting for $48.39 \%$ of the total number of domestic tourists. In 2019, the number of rural tourists reached 3.9 billion, accounting for $52 \%$ of the total number of domestic tourists. According to a survey report issued by the China Tourism Administration, in the first half of 2019, the number of Chinese rural tourists has reached 1.5 billion, an increase of $10 \%$ over the previous year, and revenue has increased by 0.87 trillion yuan, an increase of 11.6 over the previous year.

\subsection{Total income and proportion of rural tourism}

Due to China's rapid economic development, the number of domestic tourists is also increasing. This has also led to a continuous increase in the number of rural tourists and the output value.

Table 2. 2012-2018 China's Rural Tourism Revenue and Proportion.

\begin{tabular}{|l|c|c|c|c|c|c|c|}
\hline & 2012 & 2013 & 2014 & 2015 & 2016 & 2017 & 2018 \\
\hline Total Rural Tourism Revenue/100 Million Yuan & 2400 & 2800 & 3200 & 4400 & 5700 & 7400 & 8000 \\
\hline Proportion of Domestic Revenue $\%$ & 8.1 & 8.7 & 9.5 & 9.9 & 11.7 & 12.5 & 13.5 \\
\hline
\end{tabular}

It can be seen from Table 2 that in 2018, China has achieved 800 billion yuan in rural tourism revenue, accounting for $13.5 \%$ of the total domestic tourism revenue.

\subsection{Total investment in rural tourism}

From the perspective of the industrial scale of rural tourism, the development of the industry has grown extremely rapidly. According to the domestic tourism industry (see Table 3), in 2015, the country' s rural tourism industry completed a total of 272.6 billion yuan in investment, which increased to 392.5 billion yuan in 2016, an increase of $47.7 \%$ over the previous year. In 2017 , the total investment in rural tourism nationwide was 560 billion yuan, an increase of $42.7 \%$ compared to the previous year.

Table 3. 2015-2017 China's Rural Tourism Investment Scale.

\begin{tabular}{|c|c|c|c|}
\hline & 2015 & 2016 & 2017 \\
\hline Investment Scale /100 Million Yuan & 2726 & 3925 & 5600 \\
\hline Growth /\% & & 47.7 & 42.7 \\
\hline
\end{tabular}

\section{Development trends of rural tourism}

The development of rural tourism in China is mainly based on rural sightseeing and leisure experience. The higher participation rate and return rate of domestic tourists are mainly due to the folk-custom tourism method of "living in a farmhouse, eating in a farmhouse, and playing in a farmhouse". At the same time, China's rural tourism has gradually diversified. Rural tourism is transitioning from a consumption model to a sightseeing holiday. The development path of rural tourism economy has gradually formed a form closer to rural life. The "Several Opinions on Further Promoting Tourism Investment and Consumption" issued by the General Office of the State Council pointed out (see Table 4) that by 2020, China's rural tourism will build 6,000 brand model villages and form more than 100,000 rural tourism characteristic villages. 3 million farmhouses.

Table 42020 China's Rural Tourism Development Plan.

\begin{tabular}{|c|c|c|c|c|}
\hline & Rural Tourism Model Village & Tourist Characteristic Village & Farmhouse & Beneficiary \\
\hline 2020 Goals & $6000+$ & $10+$ & $300+$ & 5000 \\
\hline
\end{tabular}

The future development direction of China's rural tourism is mainly manifested in three aspects.

First, local governments have significantly increased their investment in the rural tourism industry. Many places include the development of rural tourism industry in the overall plan of local economic development. The local government regards it as a major support and development target for the tourism industry.

Second, the diversification of investment in the rural tourism industry has become increasingly obvious. In such a developed tourism industry, some powerful farmers will develop corresponding business activities on their own. With the gradual expansion of China's rural tourism market, investment entities have gradually diversified, including individual operators, collective investment, or powerful companies.

The third is that the rural tourism industry has begun to focus on product characteristics, scale, and branding. Many practitioners engaged in rural tourism have completed the accumulation of original capital. They need to look for greater development opportunities and need to make their careers bigger and stronger. For new investors, if they want to gain an advantage in the new round of competition, they must adopt more innovative methods.

\section{Develop the value of rural tourism}

The development of rural tourism is a new breakthrough to solve the "three rural" problems. First of all, it can be combined with solving the "three rural" problems so that the rural tourism industry can be used to fight poverty. Secondly, rural tourism can become a brand and economic development advantage for the local area. Finally, through the organic combination of rural tourism and sustainable development of science and technology, the tourism industry can become a special industry in the countryside, enhancing farmers' awareness of wealth and environmental protection [4].

The economic value of rural tourism can be embodied in the following points. 
One is to develop rural tourism activities by making full use of rural resources, thereby broadening the sources and methods of income for farmers. Encourage farmers to participate in rural tourism activities through the use of rural natural landscapes and pastoral scenery. Farmers can transform their own means of production into products that can be managed. In addition, all business activities carried out by farmers have lower governance costs and simpler industrial methods. The experience of rural tourism development in some countries shows that rural tourism has played a huge role in promoting the economic development of rural areas. The development of rural tourism in many parts of China has also highlighted its important value for rural poverty alleviation and prosperity [5].

The second is that rural surplus labour can be absorbed to a large extent through rural tourism. Due to the extremely singular industry in rural areas, the employment of farmers is insufficient. Many farmers have been unemployed for a long time, which directly leads to the retention of a large number of surplus labours in the countryside. The development of tourism can enable farmers to re-employ without leaving their hometowns.

The third is to enhance the added value of rural agriculture and promote the development of the tertiary industry. The development of rural tourism is closely related to agricultural production. Since agricultural products directly face consumers, they can skip the intermediate circulation links and reach consumers. To a certain extent, this solves the problems such as the unblocking of the agricultural industry chain. This has also increased the demand for agricultural products to a certain extent, and has increased the added value of agricultural output from the side. This has promoted the entire rural industrial structure and provided a better platform for developing other industries in the rural areas.

The fourth is to improve the rural environment and increase the overall income of farmers. Due to the improvement of the economic level, consumers have higher and higher requirements for the consumption environment. This has played a role in promoting environmental problems in rural areas to a certain extent, for example, the sanitary conditions of accommodation, service level, food safety and infrastructure construction. To meet the needs of consumers, the rural industry will upgrade its own indicators to further improve the rural living environment [6].

The fifth is to promote the construction of spiritual civilization in rural areas. In the process of the construction of rural tourism industry, the connection of urban and rural spiritual civilization will inevitably be carried out. During the docking process, some rural villages will organize various types of rural tourism activities to enhance the influence of their own brands. Before launching activities, personnel will be trained, which effectively improves the quality level of rural people and enhances the overall development trend of various industries in the countryside [7].

Sixth, it is conducive to protecting the original ecological rural environment. The rural tourism industry mainly attracts tourists through unique rural natural characteristics and the most primitive rural customs (Figure 1). To a certain extent, this will promote farmers' protection of their own environment. In the development process of rural tourism, through a series of activities of excavation, restoration, and publicity, the environment and culture that are already on the verge of extinction or even unpopular can be vigorously discovered. To a certain extent, its cultural value has been enhanced, and the original villagers' consciousness of protecting their own culture has also been stimulated.

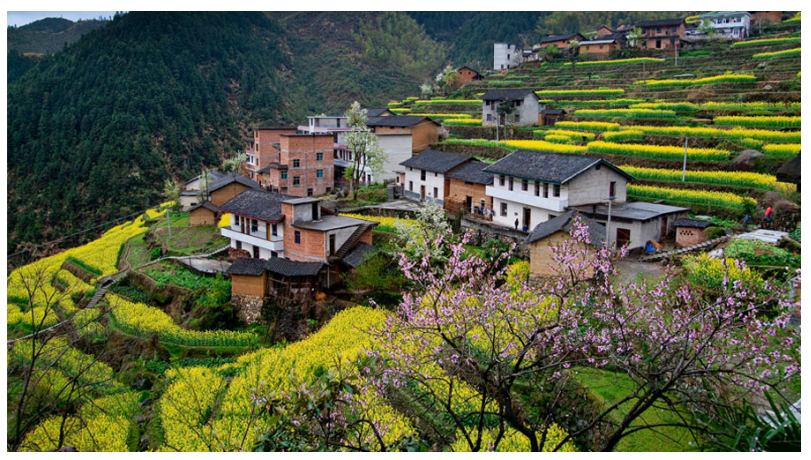

Fig. 1. Country Style.

\section{Optimized paths for the development of tourism industry}

\subsection{Pay attention to the development of rural tourism}

Tourism is a vibrant industry. The tourism industry can promote economic growth, and it can also promote the construction of local ecological civilization. From the perspective of sustainable development, the tourism industry is closely related to local economic development. The development of rural tourism is not only the development of tourism, but also includes tourism-related industries [8]. Relevant departments should incorporate the development of the tourism industry into the local economic development plan. Tourism is a service industry. The orderly development of rural tourism has also promoted the healthy development of cities. To some extent, rural tourism is conducive to the construction of a harmonious society. Rural tourism can also reduce employment pressure and have a good improvement effect in transferring surplus labour. In addition, rural tourism has a good coordination effect on the development of other industries.

\subsection{Build a characteristic tourism industry}

Culture is a symbol of a city or region. Culture can also drive the development and transformation of related industries. Tourism depends on the abundance of cultural resources. High-quality cultural activities and resources are a huge attraction for tourists. No matter which region, the tourism industry will form a good promotion relationship with the local characteristic culture. Therefore, the development of rural tourism must strengthen the integration of culture and tourism. It is 
necessary to increase the cultural connotation of tourism. In addition, you can make full use of the momentum of the tourism industry to accelerate the process of cultural industrialization.

\subsection{Establish the concept of sustainable development}

The development of rural tourism in China has strong development advantages. In some respects, rural tourism also has strong room for development. The relevant local departments should rationally integrate, plan and build the local tourism resources. In this way, the local tourism resources will be built into a tourism industry with higher quality, better environment and distinctive features. Otherwise, disorderly development will only destroy the local ecological environment, and will also lead to a decline in the development of the local tourism industry. In this way, rapid economic development cannot be achieved. Disorderly development cannot highlight the characteristics of the local tourism industry, and even waste the tourism resources in the region. The evaluation indicators of the tourism industry should include economic growth, quality improvement, and related contributions to other industries. At the same time, in terms of environmental protection, the local government must establish a sustainable development concept. Green water and green mountains are Jinshan Bank.

\section{Conclusion}

The purpose of optimization and upgrading of the rural tourism industry is to make better use of rural resources. Giving play to the resource advantages of the countryside is conducive to optimizing the industrial structure of the countryside, and at the same time it can also increase the income level of farmers, which is of great significance to the economic development of rural areas. With the implementation of the rural revitalization strategy, the development of the rural tourism industry is also facing higher requirements and more severe challenges. In view of the current problems in the development of rural tourism industry, it is necessary to conduct more in-depth discussion and improvement. Only by continuously optimizing the industrial structure of rural tourism can rural tourism develop sustainably and healthily.

\section{Acknowledge}

Project source: 2020 Weifang Science and Technology Development Plan. Project Title: Research on the Rural Development Model of Scientific and Technological Innovation from the Perspective of Supply Chain. Project number: 2020RKX177.

\section{References}

1. Geng Songtao, Zhang Shenyang, Research on the coordinated development of rural tourism and cultural industry under the background of rural revitalization, Journal of Nanjing Agricultural University (Social Science Edition), 2021, 21(02): 44-52.

2. Qu Xueshu, Jiao Lihui, Research on the upgrade path of rural tourism industry under the background of rural revitalization, Economic Issues, 2020(12): 108-113.

3. Zhong Huamei, Theoretical analysis of the integrated development of rural tourism industry under the background of cultural and tourism integration, Resource Development and Market, 2020, 36(04): 421-426.

4. Song Mingxuan, Xie Chunshan, Comparative analysis of domestic and foreign rural tourism development concepts, processes and models, Journal of Shenyang Agricultural University (Social Science Edition), 2019, 21(04): 385-391.

5. Liu Xiaoying, Research on my country's Rural Tourism Product Development from the Perspective of Industrial Convergence, Reform and Strategy, 2017, 33(09): 182-185.

6. Tang Ye, Research on my country's Rural Tourism Development from the Perspective of Global Tourism, China Agricultural Resources and Regionalization, 2017, 38(07): 207-212.

7. Wei Wei, He Beiting, Innovative model of "beautiful countryside" tourism industrial park, Journal of Northwest Sci-Tech University of Agriculture and Forestry (Social Science Edition), 2016, 16(03): 63-68.

8. Zhao Hua, Yu Jing, Research on the integration and development of rural tourism and cultural and creative industries under the new normal, Economic Issues, 2015 (04): 50-55. 